\title{
O ENFRAQUECIMENTO ÉTICO-POLÍTICO CONTEMPORÂNEO PELO VIÉS DO DIREITO
}

\author{
THE CONTEMPORARY WEAKENING OF ETHICS AND POLITICS AS A RESULT \\ OF A LEGAL BIAS
}

Wellington Tibério ${ }^{\mathrm{a}}$

Resumo Este artigo visa problematizar as relações entre "Direito" e "política" para além da pacificação que os associam em um movimento de continuidade e complementaridade. Tendo como principais referências os desenvolvimentos analíticos de Jacques Rancière e Michel Foucault, considera-se a atual judicialização das relações sociais como uma estratégia para aliviar a política de sua tarefa, na qual a noção de liberdade se torna operativa, por meio da gestão das evidências que delimitam o campo do possível. Como ponto de apoio, trabalha-se com os efeitos do avanço do Direito no interior das tensões que envolvem as relações escolares no presente. A perspectiva de análise tem como foco a possibilidade de que os embates no plano ético-político tenham espaço, o que a conduz para a consideração da "potência do não" como estratégia de luta.

Palavras-chave Direito; política; Estado; escola.

\begin{abstract}
This article intends to problematize the relation between "law" and "politics" and question the conciliation which ties them together in a movement of continuation and complementarity. Taking the analytical developments of Jacques Rancière and Michel Foucault as its main references, it considers the current judicialization of social relations as a strategy to relieve politics from its duty, in which the notion of freedom becomes operative through the management of evidences that define the field of the possible. As a support, it works with the effects of the advance of the law into the tensions surrounding the relationships at school nowadays. The perspective of analysis focuses on the possibility of the conflicts on the ethical-political level taking place, which leads to the consideration of the power of "no" as a struggle strategy
\end{abstract} Keywords law; politic; state; school.

a Formado em Geografia pela FFLCH/USP, com especialização em Direitos Humanos pela Faculdade de Direito da USP e mestrado em Sociologia da Educação pela FEusP. 
[...] viver em sociedade não envolve solidariedade, que dependeria de movimento interno dos sujeitos sociais, mas simplesmente a observância de padrões de comportamento externo que garantam a justaposição de interesses. Não é por acaso que os teóricos da sociedade política moderna se preocuparam tanto com a questão do contrato como instrumento de regulamentação objetiva da experiência coletiva.

Franklin Leopoldo e Silva (2010)

\section{APRESENTAÇÃo}

O Direito, o estabelecimento de regras que regulam o convívio social ou um sistema de normas que regulam as relações sociais, de maneira geral, é entendido como imanente à vida em sociedade, e sua expansão vista como uma conquista histórica diante de situações mais opressivas, caracterizadas se não por sua ausência, por sua restrição ou diminuição a níveis mínimos.

A partir desse entendimento, constituem-se ideias de avanço ou recuo em relação à sociabilidade, geralmente associadas à ampliação ou não de seu campo de intervenção. São comuns, nesse sentido, linearidades que estabeleçam graus de barbárie ou civilização, tendo como referência seu nível de desenvolvimento em uma perspectiva de progresso. No entanto, algumas tensões da atualidade convocam todos a pensar o Direito e seus desdobramentos para além do enquadramento instaurado pelas ideias de avanço e recuo de forma linear (mais Direito - melhor/menos Direito - pior), portanto, fora de uma perspectiva de desenvolvimento e progresso, e sim por um caminho que considere as novas batalhas e os enfrentamentos do presente, em que ele parece desempenhar um papel importante enquanto estratégia de governo.

Nessa perspectiva, Jacques Rancière (1996, p. 110) chama a atenção:

[...] fala-se muito da extensão do Estado de direito e do campo do direito como característica de nossos regimes. Mas, para além da concordância sobre a ideia de que a regra é preferível ao arbitrário e a liberdade à servidão, resta saber quais fenômenos são exatamente designados por esses termos. [...] a simples celebração do Estado de direito entra então nas cômodas abreviações que permitem, em face do não-direito dos Estados arqui-policiais, unir todos esses "direitos" heterogêneos num único reino não-questionado do direito, feito da harmonia 
feliz entre a atividade legislativa do poder público, os direitos dos indivíduos e a inventividade processual dos escritórios de advocacia.

Portanto, para além da possível concordância em um nível genérico e abstrato de que algumas situações e condições são eventualmente melhores do que outras, a existência de um "reino não questionado" do Direito, que, nesses termos, se pode considerar como delineado por uma espécie de consenso, é aqui entendida como algo que precisa ser colocado em questão enquanto condição de possibilidade para escapar das táticas de gestão do pensamento em funcionamento no presente.

Propõe-se, então, não fazer coro à simples celebração da expansão do Direito que constitui a judicialização das relações sociais do presente, o que não significa considerá-la desprezível ou posicionar-se contrário à invenção de referências para a vida em comum, mas, tão somente, deslocar-se em relação às cômodas abreviações que instauraram um consenso em torno do Direito como "princípio pelo qual tudo vem a ser" em uma sociedade e, assim, investir em seu descentramento, tendo como perspectiva abrir espaço para o fortalecimento de relações que se constituam no plano ético-político.

As principais referências desse exercício de problematização do papel do Direito no âmbito das relações sociais, tendo como foco seus efeitos no campo da política, serão algumas formas de como ele vem sendo demandado e utilizado no interior das tensões que envolvem as relações escolares no presente.

\section{JUDICIALIZAÇÃO DAS RELAÇÕES ESCOLARES: AS EVIDÊNCIAS E 0 CONSENSO}

Ao que tudo indica, vem crescendo nas escolas o encaminhamento de suas tensões para a esfera jurídica. Há uma clara demanda, por parte de professores e administradores das instituições de ensino, de normas jurídicas que teriam o tão sonhado poder de resolver todos os seus problemas. Em nome da indefinida "qualidade de ensino", avoluma-se sobre as costas de todos os que vivem a experiência escolar uma série de iniciativas jurídicas, sempre bem intencionadas.

A desconfiança que sustenta esse trabalho é de que o movimento que encaminha as tensões escolares para a esfera jurídica funciona como uma forma de "sabedoria que alivia a política de sua tarefa", nos termos utilizados pelo filósofo Jacques Rancière (1996, p. 112), e, assim, deixa de haver a necessidade de implicação ética com os encaminhamentos a serem tomados, o que tem o efeito de tornar desnecessário, e até inconveniente, o exercício do pensamento. 
Como forma de adentrar mais claramente no que aqui está em questão, apresenta-se um recente encaminhamento para a esfera jurídica de problemas que se referem ao cotidiano das relações escolares:

A Câmara dos Deputados analisa o Projeto de Lei 267/11, da deputada Cida Borghetti (PP-PR), que estabelece punições para estudantes que desrespeitarem professores ou violarem regras éticas e de comportamento de instituições de ensino. Em caso de descumprimento, o estudante infrator ficará sujeito a suspensão e, na hipótese de reincidência grave, encaminhamento à autoridade judiciária competente.

A proposta muda o Estatuto da Criança e do Adolescente (Lei 8.069/90) para incluir o respeito aos códigos de ética e de conduta como responsabilidade e dever da criança e do adolescente na condição de estudante (OliveIRA, 2011) ${ }^{1}$.

Cabe observar que tal encaminhamento não se trata de um exercício excêntrico do poder de propor leis do mandato da referida deputada, prática comum na instituição à qual pertence, mas de um atendimento a uma demanda de grande parte dos professores. Para se ter uma ideia, no site de onde foi retirado o texto citado, há centenas de manifestações de apoio ao que, em linhas gerais, se considera "tão nobre iniciativa”. Como ilustração dessa espécie de consenso que se criou acerca dos benefícios do encaminhamento jurídico para os problemas e dificuldades a serem enfrentados na educação contemporânea, seguem apenas os três primeiros comentários encontrados:

1 - Como professor de rede pública há 19 anos (e dois em cursos, totalizando 21), eu sei o quanto esta lei é tanto urgente como imprescindível. Não se pode descrever o horror das humilhações e coações morais, só quem passou sabe... Obrigado Deputada!!!!!!

2 - Estas agressões, abusos, ameaças estão assassinando o professor vivo! Muitos já desistiram; muitos estão de licença, fazendo tratamento, muitos estão abandonando o oficio. CHEGA DE ALUNO ABUSADO E SEM PRINCÍPIOS!!! Projeto Lei de RESPEITO ao professor deve ter URGÊNCIA!!!! Conte comigo! Estamos juntos.

1 O Projeto de Lei n. 267, de 2011, foi publicado no Diário da Câmara dos Deputados no dia o9/02/11 e pode ser consultado em: <http://imagem.camara.gov.br/Imagem/d/pdf/DCDo9FEV2011. pdf\#page $=188>$. 
3 - Há 15 anos em sala de aula, e com um processo rolando por ameaça de morte, por parte de um aluno, estou muito contente e espero que este projeto deixe o papel e chegue à sala de aula, para podermos ter um suporte contra a falta de educação e limites que hoje correm soltos pelas nossas escolas! Obrigada deputada Cida Borghetti (Oliveira, 2011).

O pano de fundo desses comentários é claramente um “desinvestimento" no enfrentamento ético dos problemas e das tensões que permeiam as relações escolares. O respeito ao professor, algo antes imposto pela força (se é que isso produzia respeito, e não medo) ou conquistado pela habilidade de um professor dedicado e seguro de seus compromissos e responsabilidades, sempre de maneira circunstancial, com atenção e sensibilidade voltadas para as situações concretas que se constituíam de maneira singular, aberto a negociações e aos desencontros, mas garantidor do mínimo que constituía uma relação de confiança necessária entre alunos e professores, passou agora a ser uma questão de Estado, e não por um viés opressivo, que expropria os professores de seus afazeres contra sua vontade, mas por solicitação dos próprios.

É claro que a realidade mudou, mas o problema talvez seja o fato de que a construção cotidiana e circunstancial do respeito dá trabalho, exige dedicação e sensibilidade. As dificuldades da realidade, em grande parte gerada por maneiras de olhar e entender as dinâmicas das relações sociais, especialmente nas escolas, também podem ser encaradas como tensões que nos convocam a estranhar esse mundo que criamos e, assim, quem sabe, caminharmos de forma um pouco mais leve nesse percurso incerto que chamamos de vida.

Verifica-se, no entanto, que a tal realidade, e suas evidências tidas como indiscutíveis, tem servido para a produção de um conservadorismo abrigado pelas referências progressistas da democracia. Com o intento de se construir um mundo melhor, muitas vezes, o que vem se produzindo são mais formas de controle e vigilância em nome da segurança; remédios e tutelas em nome da felicidade; medos e perigos em nome do bem-estar; monitoramentos e guerras em nome da paz, disseminando a mediocridade e a fraqueza como qualidades de nosso tempo. Por isso se faz fundamental no presente estarmos atentos aos redimensionamentos dos jogos de poder e às sofisticações de suas estratégias de captura, pois tudo isso ocorre não mais de forma opressiva, mas por estímulos, positivamente, em nome do bem de todos e de cada um.

Pode-se entender, nesse sentido, que a força do que se apresenta como evidência de uma dada realidade está em tornar desnecessário o exercício do 
pensamento ou, talvez, reduzi-lo apenas ao pensável ${ }^{2}$, funcionando como uma estratégia eficaz de produção do consenso. Várias abordagens que se produzem sobre as relações escolares, por exemplo, mostram que elas se utilizam de "evidências" para legitimar "inequívocos" encaminhamentos. Portanto, não se faz mais necessária a figura de um poder repressor, impositivo, basta uma certa gestão das evidências para que se conquiste a gestão do possível, pois, assim, no exercício da nossa liberdade, simplesmente constatamos as evidências e encaminhamos o que se apresenta como possível. Sobre isso, o filósofo Michel Foucault chama a atenção, em seu curso/livro intitulado Segurança, território e população, de que a liberdade entrou nos cálculos do poder, tornando-se "um elemento indispensável à própria governamentalidade" (FoucAult, 2008, p. 475).

Nesse exercício de problematização aqui em curso, parte-se da referência de que é uma armadilha a consideração de que nosso olhar é livre de antemão e de que, dessa forma, baseia-se em uma suposta realidade dos fatos (as evidências). Assim, enquanto estratégia analítica, considera-se que é no exercício de reconhecimento e estranhamento de tudo que o constrange, no mesmo movimento que o torna possível, que se abre a possibilidade de exercícios de liberdade. Jorge Larrosa (2002, p. 83) sobre isso diz:

Grande é, sem dúvida, o poder das evidências. Mas Foucault empenhou-se em mostrar a contingência das evidências e a complexidade das operações de sua fabricação. O que todo mundo vê nem sempre se viu assim. O que é evidente, além disso, não é senão o resultado de uma certa dis-posição do espaço, de uma particular ex-posição das coisas e de uma determinada constituição do lugar do olhar. Por isso, nosso olhar, inclusive naquilo que é evidente, é muito menos livre do que pensamos.

Daí o convite a não se deixar conduzir pela força das evidências: "Talvez o poder das evidências não seja tão absoluto, talvez seja possível ver de outro modo” (LARrosa, 2002, p. 83). Um convite, portanto, ao exercício do pensamento que nos desaloje de nossas certezas e, assim, amplie o campo do possível.

Nessa perspectiva, continua-se com o filósofo Jacques Rancière, que afirma, em seu livro $O$ desentendimento, no qual problematiza, entre outras coisas, o papel do direito na sociedade contemporânea, que "o consenso, antes de ser a virtude

2 Essa ideia baseia-se no trabalho de Cintya Ribeiro acerca do pensamento em Michel Foucault, no qual "o pensamento, numa investida estética, ética e política, seria sempre uma ultrapassagem do pensável” (RIBEIRO, 2006, p. 112). 
razoável dos indivíduos e dos grupos que se põem de acordo para discutir seus problemas e compor seus interesses, é um regime determinado do sensível, um modo particular de visibilidade do direito como arkhé da comunidade" (RANCIÈRE, 1996, p. 110).

Essa linha de entendimento do Direito como princípio e fim da comunidade, como origem de sua existência, tem em sua base a noção de lei como ordenadora geral das particularidades, a qual possui a pretensão de fazer o particular entrar na esfera de sua universalidade (RANCIÈRE, 1996). Nesses termos, pode-se observar que, se, por um lado, a lei como ordenadora geral visa eliminar injustiças advindas das particularidades de certos interesses, ela também arma um campo de enquadramento do singular na referência normalizadora do suposto universal. Tem-se, aqui, um complexo problema, o qual não será alvo no momento, porém, para que os embates vividos no plano ético-político tenham algum espaço, isso sim interessa, é preciso exercitar estrategicamente um deslocamento do olhar, para então inventar a possibilidade de ver de outro modo.

Por esse caminho, é possível considerar que esse "universal” do jurídico é um particular universalizado, o que viabiliza a compreensão de que o Direito é, então, operativo para certas particularidades que almejam se impor como universais. Dessa forma, faz-se necessário, com vistas ao que interessa, que todo o suposto universal do jurídico seja torcido em sua "universalidade”, pois, amparado pela formalidade da lei, o que há é, em grande medida, uma estratégia que visa tornar o particular imune a questionamentos e litígios ${ }^{3}$.

Esse particular tornado universal pelo Direito, em grande medida, torna-se imune a questionamentos e litígios em razão de um movimento de naturalização do próprio Direito, da própria lei. Após sua instauração, precedida por inúmeras disputas e embates, eles são apagados, e geralmente estabelece-se uma relação de circularidade entre natureza e lei, compondo, assim, um sistema consensual no qual não há espaço para novos litígios. Tendo a legalidade como referência, produz-se uma convergência de opiniões, por meio do que Rancière nomeou de "regime da opinião", que torna desnecessária a prática do pensamento, a experiência do litígio vivida de forma circunstancial, o embate enquanto divergência no

3 Esse termo será utilizado tendo como referência seu emprego por Jacques Rancière, em $O$ desentendimento (1996), que o qualifica, em linhas gerais, como disputas e embates que ocorrem no plano político.

4 Tem por princípio fazer desaparecer a aparência conturbada e perturbadora do povo. "Opinião pública" como idêntica ao corpo do povo, assim ele se faz totalmente presente, mas de fato está totalmente ausente (RANCIÈRE, 1996). 
plano ético-político. Trata-se da produção e gestão do consenso como estratégia administrativa de governo.

\section{O SUJEITO POLÍTICO COMO SUJEITO DE DIREITO}

O filósofo Michel Foucault anunciou, na forma de uma impressão, algo que interessa muito no desdobramento da análise em curso:

[...] tenho a impressão de que no pensamento político do século XIX - e talvez fosse preciso retroceder mais ainda, a Rousseau e a Hobbes - o sujeito político foi pensado essencialmente como sujeito de direito, quer em termos naturalistas, quer em termos do direito positivo. Em contrapartida, parece que a questão do sujeito ético é alguma coisa que não tem muito espaço no pensamento político contemporâneo (Foucault, 2004, p. 279).

Portanto, Foucault levanta a suspeita de que o "sujeito político" moderno tenha sido pensado como "sujeito de direito", e não como "sujeito ético". Nesse caso, ser pensado significa ser produzido. Ao que tudo indica, essa suspeita de Foucault é diuturnamente confirmada pelo modo de funcionamento da educação escolar no presente, na qual há vários indícios de que o sentido da produção do sujeito tem promovido um empobrecimento das formas de vida por meio de um enfraquecimento das possibilidades formativas dos embates encaminhados no plano ético-político.

Nesse sentido, como já exposto, vê-se hoje em dia nas escolas um crescente enquadramento das divergências e de possíveis enfrentamentos ético-políticos no campo jurídico da adequação à formalidade da lei. Cabe reafirmar que, em grande medida, isso decorre da reivindicação dos próprios professores, que passaram a entender como necessário e fundamental um reforço legal à sua possibilidade de atuação. Pode-se acrescentar, no entanto, que tal movimento vem redundando, entre outras coisas, em um enfraquecimento do ser professor, tornando-o pequeno, impotente, ao endossar o que se nomeia atualmente como "judicialização das relações escolares".

Nesse sentido, considera-se que a prática de normatização como recurso usado no "jogo da verdade", que se desenvolve na prática educativa, em grande medida reivindicada pelos próprios professores como uma tentativa, atualmente, desesperada, de fortalecimento de sua posição e possibilidade de ação, tem proporcionado, na forma de um "tiro que sai pela culatra", um efeito de enfraquecimento, 
expondo sua insegurança e falta de habilidade em lidar com as tensões de forma circunstancial e, assim, perdendo a oportunidade de produção de uma relação fundada na ética, ao mesmo tempo em que coloca em ação, voluntariamente, o que se pode reconhecer como um circuito de legitimação estatal.

Como forma de tornar essa questão mais compreensível, observe-se uma tensão contemporânea banal vivida no interior das escolas: o uso do telefone celular. Sua proibição em sala de aula foi instituída por uma lei estadual, em São Paulo5. Essa lei, em grande medida reivindicada pelos professores e comemorada por eles quando publicada, é claramente um atestado ou um endosso, por sua própria parte, de sua fraqueza, portanto, uma iniciativa que tem como efeito a produção do enfraquecimento da prática docente, defendido pelos próprios professores. Considera-se que tal encaminhamento funciona como uma afirmação da suspeita anteriormente citada de Michel Foucault. Isso porque o não uso do telefone celular em sala de aula, algo possível de ser reconhecido como razoável, poderia ser construído localmente, como um exercício de litígio conduzido no plano ético-político e, portanto, como uma prática de fortalecimento do papel de professor com base na coragem de um enfrentamento ético do problema, um litígio que poderia ser circunstancialmente conduzido sem a necessidade de um ordenador geral e superior das condutas, enquanto figura transcendente da lei inquestionável e/ou de um Estado atento e protetor das boas maneiras.

Amparado pelo encaminhamento jurídico do problema, o professor se coloca no lugar de simples operador da lei, não havendo necessidade de implicação ética. Entre outros efeitos, cria-se uma orientação formativa que aponta para o aluno obediente à lei transcendente e o professor dependente de um ordenador externo. Nesse sentido, tem-se que considerar que há muita diferença, tanto do ponto de vista formativo, em relação aos alunos, quanto do reconhecimento e respeito em relação aos professores, entre o estabelecimento do não uso do telefone celular em sala de aula por consideração circunstancial do caráter das relações que ali se desenvolvem ou por imposição/submissão a uma lei externa e geral.

Em certa medida, isso possui ligação com a ideia desenvolvida pelo filósofo Jacques Rancière (1996) de que há uma transformação do litígio político em

5 Lei Estadual $\mathrm{n}^{\mathrm{o}}$. 12.730, de 11 de outubro de 2007, regulamentada pelo Decreto $\mathrm{n}^{\mathrm{0}} \cdot 52.625$, de 15 de janeiro de 2008. "A medida, que já entrou em vigor em outros estados, como Pará, Rio de Janeiro, Rondônia, Ceará e Rio Grande do Sul, também poderá se tornar lei federal. O Projeto de Lei 2.246/2007, de autoria do deputado federal Pompeu de Mattos (PDT-RS), está tramitando na Câmara dos Deputados e poderá vetar o uso do aparelho celular não só pelos alunos, mas por todos dentro das escolas. Segundo especialistas, o uso do celular em sala de aula pode causar a distração do aluno, afetar o rendimento escolar das crianças e atrapalhar a didática dos professores" (JUSBRASIL, 2010). 
problema jurídico, como uma forma de sabedoria que alivia a política de sua tarefa. Por essa perspectiva, tem-se, portanto, uma entrada para pensar as relações entre o Direito e a política, que procura escapar à pacificação que os associa, em um movimento de continuidade e complementaridade. Especialmente na dinâmica escolar, há vários indícios de práticas e encaminhamentos de divergências por um caminho que se pode considerar como de despotencialização da política, o que, em grande medida, não corresponde às ideias de esvaziamento dos fundamentos da noção de cidadania (vinculada ao binômio direitos e deveres), abordagem geralmente comum nas análises sobre a educação, no presente, mas, ao que tudo indica, ao seu contrário.

É muito presente nas escolas a utilização da noção de cidadania como forma de legitimar a obediência, e, assim, o "cidadão consciente" é o indivíduo que obedece às regras jurídicas, operando estrategicamente a produção do sujeito político como sujeito de direito, o que corrobora com a suspeita de Foucault de que "parece que a questão do sujeito ético é alguma coisa que não tem muito espaço no pensamento político contemporâneo" (Foucault, 2004, p. 279).

\section{A SUBMISSÃO DO POLÍTICO AO ESTATAL PELO VIÉS DO JURÍDICO}

Verifica-se, no presente, que a ideia de "aliviar a política de sua tarefa”, ou da diminuição de seu campo de atuação, ou, ainda, da redução de sua relevância na vida em sociedade, é geralmente atribuída apenas às exigências impostas pela economia. No entanto, em um momento histórico em que algumas fronteiras entre esquerda e direita estão borradas, em que certas diferenças estão se diluindo, interessa seguir a trilha de algumas análises atentas aos redimensionamentos contemporâneos das estratégias de poder. É nesse sentido que Rancière desenvolve uma problematização na qual considera a regra jurídica, ou o Direito, como operador de um “'ausentamento' do demos”, de uma eliminação do campo de descontinuidade em que possa se desenvolver o litígio e, assim, portanto, de um "ausentamento" da própria política. A partir, então, de uma perspectiva que se desloca da abordagem habitual, pode-se tentar dimensionar as novas configurações do campo de batalha e, assim, quem sabe, redimensionar os exercícios de resistência e as práticas de liberdade.

Nesse sentido, para além da economia (chave recorrente no interior da esquerda), propõe-se considerar a atividade de multiplicação e de redefinição

6 Expressão utilizada por Rancière, em O desentendimento (1996). 
dos direitos, empenhada em colocar direito, regra de direito e ideal jurídico em todos os circuitos da sociedade, em adaptar-se a todos os seus movimentos e em antecipá-los, como uma estratégia política de ausentar a própria política.

Todo esse movimento contemporâneo caracterizado como de "judicialização das relações sociais" deve ser compreendido, especialmente no Brasil, no interior das lutas e reivindicações desencadeadas em sua história recente contra a ditadura militar, que, em linhas gerais, almejavam uma fundamental submissão das forças do Estado à regra jurídica. No entanto, longe de defender regimes deliberadamente autoritários e opressores, e, sim, problematizando os redimensionamentos das estratégias de governo no presente, precisa-se atentar para o que afirma Rancière, ao se referir aos Estados de direito contemporâneos:

[...] essa pretensa submissão do estatal ao jurídico é antes uma submissão do político ao estatal pelo viés do jurídico, o exercício de uma capacidade de desapossar a política de sua iniciativa, pela qual o Estado se faz preceder e legitimar. Tal é o estranho modo de legitimação que as teorias à moda do estado "modesto" encobrem. O Estado moderno, dizem, é um Estado modesto, um Estado que devolve ao jurídico de um lado, ao social do outro, tudo o que lhes tinha tomado. Mas é menos em relação a si mesmo que à política que o Estado exerce essa modéstia. O que ele tende a fazer desaparecer, por esse tornar-se modesto, é bem menos seu aparelho que a cena política de exposição e de tratamento do litígio, a cena de comunidade que colocava juntos os mundos separados (RANCIÈRE, 1996, p. 111 - grifo nosso).

Pode-se entender isso tanto no sentido ascendente como no descendente. No primeiro, há as divergências entre situação e oposição no Brasil, que cada vez mais têm o Superior Tribunal Federal como campo de disputas adequadas às exigências jurídico-legais, local composto por "sábios e peritos" que definem a validade dos litígios. No segundo, tem-se as escolas, onde os encaminhamentos diante de "situações desviantes", as quais muitas vezes são manifestações de divergências no plano ético-político, têm redundado em um reforço da vigilância e do controle policial.

Rancière aponta, portanto, para uma espécie de deslocamento no qual o Estado, ao se submeter ao jurídico, estrategicamente faz com que o campo do político se reduza à administração da necessidade definida pela norma jurídica. Esse movimento é o que esse pensador identificou como "sabedoria de transformação do litígio político em problema jurídico" (RANCIÈRE, 1996, p. 112), o que torna possível que a política funcione apenas no interior de um sistema de legitimação estatal, 
ou seja, "submissão do político ao estatal pelo viés do jurídico" (RANCIÈre, 1996, p. 111). Dessa forma, a iniciativa política é desapossada de sua força por meio de um filtro jurídico que funciona como mecanismo de garantia e fortalecimento do Estado. Portanto, o controle das forças do Estado por sua submissão ao jurídico é, antes, nessa perspectiva, o controle das forças da política pelo jurídico, por meio do qual o Estado se legitima. Nesse sentido, continua o filósofo:

Todas essas extensões do direito e do Estado de direito [...] são também extensões da capacidade do Estado perito em tornar a política ausente ao suprimir todo intervalo entre o direito e o fato. De um lado, o direito vem libertar o Estado da política [...]; de outro, ele vem colar-se a toda situação, a todo litígio possível, decompô-lo nos elementos de seu problema, e transformar as partes do litígio em atores sociais, refletindo como a lei de seu agir a identidade da comunidade consigo mesma. A extensão desse processo é a crescente identificação do real com o racional, do jurídico com o científico, do direito com um sistema de garantias que são acima de tudo as garantias do poder do Estado, a garantia sempre reforçada de sua infalibilidade, da impossibilidade de que seja injusto, a não ser por erro, um erro do qual ele não cessa de garantir-se mediante a consulta incessante de peritos sobre a dupla legitimidade do que faz. Há então uma conjunção entre três fenômenos: a judicialização proliferante, as práticas de perícia generalizada e as da sondagem permanente. O direito e o fato tornam-se tão indiscerníveis quanto a realidade e sua imagem, quanto o real e o possível. O Estado perito suprime todo intervalo de aparência, de subjetivação e de litígio na exata concordância da ordem do direito com a ordem dos fatos. Aquilo que o Estado se desfaz ao ser constantemente averiguado, o que ele reconhece continuamente aos indivíduos e aos grupos em direitos sempre novos, ele readquire como legitimação. E o poder do direito se identifica cada vez mais com essa espiral de super-legitimação do Estado científico [...] (RANCIÈRE, 1996, p. 113-114).

Nesse cenário de "judicialização proliferante", em que o fato e o Direito se tornam indiscerníveis, passa-se a ter a disseminação de uma impotência que, entre outras coisas, parece conduzir todos à mera operacionalização da formalidade como maneira de jogar no campo da produção da verdade.

É interessante verificar que atualmente se faz necessário documentar tudo para se proteger, gravar conversas, ter testemunhas, afinal, a qualquer momento, pode-se ser acusado de algo. Condizente com essa situação, segue um singelo e pequeno diálogo realizado em uma escola, na reunião do conselho de classe, sobre 
as provas que garantem uma reprovação sem chance de questionamento por parte dos alunos ${ }^{7}$ :

Professora: "Ainda bem que não houve recurso de aluno".

Coordenadora pedagógica: "Mas quando a coisa é bem amarrada não há problema, não tem como".

Professora: “Graças a Deus!”.

Tem-se, aí, de forma muito simples, uma maneira de produzir a verdade de acordo com o velho axioma jurídico, ainda extremamente operativo: "o que não consta nos autos não existe no mundo". A "amarração" à que se refere a coordenadora pedagógica refere-se ao cumprimento da formalidade definida pela regra jurídica, a qual, uma vez cumprida, pode legitimar inúmeras injustiças. Não é por acaso que o cargo de secretário nas Associações de Pais e Mestres e nos Conselhos de Escola, figura responsável por redigir as atas das reuniões, requer uma atenção cuidadosa de diretores de escola. Dessa forma, vê-se que se tornam comuns, e até mesmo necessários, à "sobrevivência" e/ou autoproteção de cada funcionário de uma escola articulações e arranjos que visam simplesmente garantir um certo controle da formalidade, pois isso significa garantir certo controle sobre o que se produz como realidade.

É interessante constatar que tudo isso, o Direito, a regra jurídica, a legalidade, não constitui uma força de atração das condutas para seu interior, nem tampouco pressupõe que assim seja; o que se produz é um aparato no qual impera a formalidade no interior da qual pode-se realizar o que se quiser, mas com uma pequena observação, o que se quiser desde que seja abrigado pela formalidade e, assim, administrado pela rede hierárquica, aberta a conchavos por meio dos quais se oferecem microbenefícios, no mesmo movimento que se constrói a legitimidade para que tudo continue funcionando da maneira como funciona. Uma estratégia política de estabilização dinâmica das forças em luta, possivelmente responsável por uma certa sensação de esvaziamento político da dinâmica social contemporânea.

Pode-se compreender, portanto, que essa formalidade cumpre aí uma função fundamental, ela constitui o próprio sistema de legitimação estatal, pois é, em grande medida, na garantia da formalidade, em sua valorização como mecanismo de funcionamento social e de estabelecimento da realidade aprisionada pelo impe-

7 Diálogo colhido durante o acompanhamento das atividades de uma escola da rede estadual de São Paulo, em dezembro de 2010. 
rativo da autoproteção e da busca pelo bem-estar, que se reafirma cotidianamente o próprio Estado.

Sobre isso, cabe uma última observação: de acordo com Foucault (2008), o desafio é não erigir o Estado como uma realidade transcendente, mas considerá-lo a partir da própria prática dos homens, a partir do que eles fazem e da maneira como pensam. Por isso ganha força a ideia de considerar a formação do Estado, no sentido moderno do termo, como um episódio importante na história do governo dos indivíduos por sua própria verdade (Foucault, 2006). A produção de verdades de si e para si atua como uma forma de governo e autogoverno capaz de vincular a ideia de liberdade a uma renúncia do presente como potência criativa e de produção de diferenças. O que se passa a ter, então, é, voluntariamente, a domesticação produzida pela certeza das evidências, pela delimitação apertada do campo de possibilidades que constitui o que se denomina realidade.

Por esse caminho, há, então, a produção das próprias verdades como um campo de batalha, não no sentido de melhores ou piores verdades, nem de querer se posicionar fora do jogo de produção de verdades, mas no sentido de movimentar o jogo, produzir diferenças, verdades momentâneas e circunstanciais, explicitamente interessadas, arbitrárias, nômades.

\begin{abstract}
Assim, se a verdade sempre se produziria e se reproduziria no campo dos jogos de verdade, não existindo naquela nada que pudesse ser da ordem do intangível e do absoluto, escrita que estaria insistentemente em relações de força reguladas pela microfísica do poder (conforme Foucault no livro Microfísica do poder), isso implica, evidentemente, a possibilidade sempre colocada para se transformar as economias presentes nos jogos de verdade (Birman, 2002, p. 308).
\end{abstract}

Cabe acrescentar: possibilidade que se abre por meio do exercício ético-estético do pensamento enquanto estranhamento e ultrapassagem do pensável.

\title{
CONSIDERAÇ̃̃ES FINAIS
}

A partir de uma atenção dedicada às tensões contemporâneas entre direito e política e seus efeitos, pode-se considerar que, ao invés de se produzirem formas de vida fortalecidas pelos confrontos no plano ético-político, tem-se produzido formas de vida enfraquecidas pela submissão à determinação normativa e aos conchavos necessários à autoproteção. Isso talvez esteja na base de um estreitamento da ação política no presente, que a tem restringido à garantia da formalidade 
e à conveniência individual. Tendo as evidências de uma realidade entendida como inquestionável na articulação estratégica da produção do consenso acerca do que se apresenta como necessário, tem-se disseminado a regulação jurídica das relações sociais em detrimento da coragem do enfrentamento ético-político de nossas tensões. No exercício de nossa liberdade, tem-se reivindicado cada vez mais tutela, índice do apequenamento das formas de vida que se está produzindo no presente.

Diante dessa situação, é preciso considerar que se constitui um plano de luta no que se pode entender como interesses próprios. Se a força das estratégias de poder do presente estão na consideração da liberdade, também aí está sua fraqueza. Nesse sentido, pode ser interessante atentar para a proposta do exercício do "poder de não querer" na chave de um "exercício de descriação" (PELBART, 2008), uma espécie de não afirmativo que atue como força que abre espaço, brechas, vãos, diante das certezas e do modo contínuo que criam uma superfície regular e apertada para os encaminhamentos diários que dão forma às relações sociais no presente e, em especial, à instituição escolar contemporânea.

Afinal, de acordo com Rancière (1996, p. 136), “a comunidade política é uma comunidade de interrupções, de fraturas, pontuais e locais”, e não algo estabelecido pela continuidade consensual definida pela judicialização das relações sociais, a qual pretende produzir relações sem espaços vazios, sem vãos. Esse filósofo aponta para uma comunidade política como tendo "intervalos de subjetivação", os quais “o estar-junto político é um estar-entre: entre identidades, entre mundos" (RANCIÈRE, 1996, p. 136). Complementa o autor: "Os intervalos políticos criam-se ao separar uma condição de si mesma [...]. Uma comunidade política não é a atualização da essência comum ou da essência do comum. É a comunhão do que não está dado como em-comum" (RANCIÈRE, 1996, p. 136).

Esse entendimento desenvolvido por Rancière desdobra-se na ideia de que "a política, em sua especificidade, é rara. É sempre local e ocasional” (RANCIÈRE, 1996, p. 138). É, portanto, da ordem da construção singular dos litígios, do enfrentamento circunstancial das dificuldades que se apresentam, sobre as quais não há especialistas.

Nesse sentido, sobre as tensões contemporâneas e, especialmente, a dinâmica escolar e suas possibilidades expansivas de vitalidade, pode ser interessante atentar para a sugestão de Hakin Bey (2004, p. 22): "Por ora, concentramos nossas forças em “irrupções' temporárias, evitando enredamentos com ‘soluções permanentes””. 


\section{REFERÊNCIAS BIBLIOGRÁFICAS}

BEy, Hakim. TAZ: Zona Autônoma Temporária. São Paulo: Conrad, Coleção Baderna, 2004. Birman, Joel. Jogando com a verdade: uma leitura de Foucault. Physis, Revista de Saúde Coletiva, Rio de Janeiro, v. 12, n. 2, p. 301-324, 2002.

FoucAult, Michel. A ética do cuidado de si como prática da liberdade. In: Foucault, Michel. Ética, sexualidade, política. Ditos e escritos V. Rio de Janeiro: Forense Universitária, 2004. p. 264-287.

Omnes et singulatim: uma crítica da razão de Estado. In: Foucault, Michel. Estratégia, saber-poder. Ditos e Escritos IV. Rio de Janeiro: Forense Universitária, 2006. p. 355-385.

. Segurança, território e população. São Paulo: Martins Fontes, 2008.

JuSBRASIL. Lei estadual proíbe uso de celular em sala de aula, 2010. Disponível em: <http:// www.jusbrasil.com.br/politica/2652907/lei-estadual-proibe-uso-de-celular-em-salade-aula>. Acesso em: 21 de janeiro de 2011.

Larrosa, Jorge. Tecnologias do eu e educação. In: Silva, Tomás Tadeu da (Org.) O sujeito da educação - Estudos foucaultianos. Petrópoles: Vozes, 2002. p. 35-86.

Oliveira, Amannda. Câmara analisa projeto de lei que pune violência contra o professor, 2011. Disponível em: <http://www.blogfalandofrancamente.com/2011/04/camaraanalisa-projeto-de-lei-que-pune.html>. Acesso em: 10 de maio de 2012.

Pelbart, Peter Pál. A potência de não: linguagem e política em Agamben. In: Furtado, Beatriz; Lins, Daniel (Org.) Fazendo rizoma. São Paulo: Hedra, 2008. p. 11-23.

RAnciÈre, Jacques. O desentendimento - política e filosofia. São Paulo: Ed. 34, 1996.

Ribeiro, Cintya Regina. A experiência do pensamento em Michel Foucault: conversações com o campo educacional. 148 p. 2006. Tese (Doutorado em Educação) - Faculdade de Educação da Universidade de São Paulo. São Paulo, 2006.

SiLvA, Franklin Leopoldo e. Viver junto. Revista E, São Paulo: SESC, n. 158, p. 23-24, 2010.

Recebido para publicação em 20/07/12. Aceito para publicação em 17/08/13 